\title{
PRESENTACIÓN MONOGRÁFICA DE PSICOLOGÍA JURÍDICA
}

\author{
Eric García López* \\ Universidad Autónoma de Oaxaca, México \\ Luz Anyela Morales Quintero** \\ Universidad Autónoma de Puebla, México
}

En los últimos años el incremento de la violencia, de la delincuencia y del daño ocasionado a las víctimas, ha motivado el interés de académicos, de estudiantes, de los gobiernos de los Estados y de la sociedad en general, por prevenirlos. Esta situación ha dado lugar a un aumento progresivo de la producción científica en torno al estudio del comportamiento y de los procesos psicológicos de diversos actores en el ámbito legal, que confirman el importante nivel de desarrollo que tiene el área de la Psicología Jurídica en Hispanoamérica.

En este marco de expansión, y en concordancia con la misión de la Revista Diversitas, este monográfico es una valiosa oportunidad para hacer visibles las reflexiones y conocimientos generados por investigadores del área de la Psicología Jurídica en países como Colombia, España y México, a través de la colaboración en contextos regionales e internacionales.

Los artículos contenidos en este número reflejan líneas relevantes y actuales de investigación, que van más allá del estudio de los responsables de delitos violentos (tema frecuente en el campo de la Psicología Legal); y que incluyen una panorámica integral en la que se enfatizan el análisis victimológico, la preocupación por los profesionales que atienden tanto a agresores como a víctimas, y el Sistema de Justicia, a través de un papel más formativo que retributivo, en el que se abren diversas posibilidades alternativas a la judicialización y promotoras de la solución pacífica de conflictos.

\footnotetext{
Doctor en Psicología Clínica, Legal y Forense por la Universidad Complutense de Madrid. Director de Investigación y Posgrado, Universidad Autónoma de Oaxaca, México. Correspondencia: Torre de Rectoría, Secretaría Académica; Av. Universidad S/N, Ex-Hacienda de 5 Señores, Oaxaca, México. C.P. 68120. ericgarcia@derechoshumanos.com.

** Candidata a Doctora en Psicología Social por la Universidad Autónoma de Madrid. Coordinadora Académica Licenciatura en Criminología, Facultad de Derecho y Ciencias Sociales. Benemérita Universidad Autónoma de Puebla, México. Correspondencia: Av. San Claudio y Boulevard de la 22 sur Col. San Manuel, Ciudad Universitaria, Facultad de Derecho y Ciencias Sociales, Edificio de Postgrados, Puebla, Pue. México. anyela.morales@fcs.buap.mx.
} 
Los autores abordan las problemáticas Psico-Jurídicas desde una perspectiva sistémica donde los fenómenos no pueden ser vistos con un lente meramente individual, sino que son contextualizados dentro de una realidad que por naturaleza es social.

Aunque desde diferentes perspectivas, los autores de este monográfico coinciden en señalar la importancia de: identificar los factores asociados con el comportamiento delictivo y con las secuelas del delito en las víctimas; aunar esfuerzos en el diseño y aplicación de protocolos de prevención del fenómeno delictivo y de sus efectos; adaptar los programas a las características y condiciones propias de las personas a quienes van dirigidos y; generar y aplicar conocimientos basados en la evidencia científica.

Otro punto compartido por los artículos aquí recopilados es la importancia otorgada a las medidas y evaluaciones objetivas de las variables psicológicas estudiadas en el mundo del Derecho. A este respecto, es de destacar la utilización de instrumentos diseñados específicamente para la evaluación de problemáticas en contextos legales, tales como el maltrato infantil, las secuelas psicológicas del delito en las víctimas, el riesgo de violencia (sexual y familiar) y la conducción temeraria, entre otras. Es evidente que la adopción de estos instrumentos en el mundo hispano provee claves significativas en los esfuerzos de prevención de la delincuencia y de la victimización. Sin embargo, este aspecto también se vislumbra como un punto sensible y susceptible de mejoras, dado que aún se requiere mayor investigación dedicada al diseño y validación de instrumentos apropiados al ámbito jurídico de los contextos latinoamericanos.

También es de destacarse la inclusión, tanto de hombres como de mujeres, en las muestras de poblaciones analizadas en los artículos, acorde con la sentida necesidad de realizar estudios de género. Tal es el caso de investigaciones sobre hombres y mujeres infractores; y el de estudios sobre víctimas que en el análisis de delitos de violencia familiar -que tradicionalmente se relaciona con víctimas mujeres- ha incluido una muestra de hombres. Además, es interesante el abordaje de temas poco frecuentes, pero no menos importantes en el área de la Psicología Jurídica, como la reflexión sobre las razones de vinculación en grupos armados; la relación entre personalidad, estilos de conducción, multas y accidentes; y la importancia de técnicas psicoterapéuticas como el bioffeedbak y la escritura emocional autorreflexiva para proteger la confidencialidad y exonerar de responsabilidad legal a funcionarios del Sistema de Justicia.

Temas como los tratados en este monográfico, apoyan la idea de que la Psicología Jurídica puede contribuir al proceso de administración e impartición de justicia, ya que el sustento científico y el proceso histórico de esta disciplina permiten avances significativos en la atención a víctimas del delito, los procesos de mediación, la evaluación psicopatológica con fines forenses, la perfilación criminológica, y un amplio campo de trabajo e investigación en todo aquello que implica el análisis del comportamiento humano en los ámbitos vinculados al Derecho, en todas sus expresiones.

Sin embargo, para que la Psicología Jurídica contribuya a los propósitos de mejoramiento de los sistemas de justicia, es indispensable la reflexión respecto a la necesidad de una estructuración más objetiva de su ejercicio, una actuación certificada de sus operadores, una presencia acreditada ante los tribunales y una legislación actualizada que reconozca la contribución de esta disciplina científica a la procuración y administración de justicia. En esta línea, la estructuración objetiva del ejercicio de la Psicología Jurídica implica que 
los fundamentos teóricos y la aplicación de esta disciplina cuenten con el respaldo de la investigación científica.

Por su parte, la actuación certificada de los operadores en el ámbito de la Psicología Forense debe darse a partir de criterios claros y precisos para su ejercicio y un Cuerpo Colegiado con carácter vinculatorio que regule las actuaciones de la práctica pericial, fomente el fortalecimiento de la práctica forense y limite el intrusismo, la malpraxis, etc. El planteamiento de este punto, es de por sí el resultado lógico del avance de la Psicología Jurídica, que trae consigo retos derivados de su práctica profesional.

La presencia acreditada de los Psicólogos Jurídicos ante los tribunales es uno de los efectos de los dos puntos anteriores. Que la voz de la Psicología Jurídica sea necesaria en el foro, que el fundamento del informe pericial influya en la decisión del Magistrado, que la víctima sea atendida con entrega profesional, que el agresor sea evaluado y atendido objetivamente, son algunos de los objetivos infranqueables que debe alcanzar la Psicología Jurídica y Forense en América Latina.

Por último, la legislación que reconoce las contribuciones de la Psicología Jurídica puede entenderse como aquella que abre sus criterios categoriales a la comunicación, de igual a igual, con otras disciplinas; que no limita el ejercicio de jerarquías al corporativismo sino que incluye otros saberes científicos, especialmente en lo que se refiere a la justicia restaurativa y a la defensa de los derechos humanos.

Confiamos en que los artículos aquí recopilados contribuyan a estas reflexiones, motiven el intercambio académico de los profesionales que investigan o ejercen en el ámbito aplicado, promuevan la prevención y reducción del fenómeno delictivo y del daño sufrido por las víctimas, y en general, motiven de alguna manera, la generación, difusión y aplicación del conocimiento derivado de la psicología para el mejoramiento de los Sistemas de Justicia. 